\title{
Assessment of Oral Health-Related Quality of Life and Its Associated Factors among the Young Adults of Saudi Arabia: A Multicenter Study
}

\author{
Ashokkumar Thirunavukkarasu $\left(\mathbb{D},{ }^{1}\right.$ Abdulaziz M. Alotaibi, ${ }^{1,2}$ Ahmed H. Al-Hazmi, ${ }^{3}$ \\ Bashayer F. ALruwaili, ${ }^{3}$ Mohammad A. Alomair, ${ }^{4}$ Waleed H. Alshaman, ${ }^{1,5}$ \\ and Amjed M. Alkhamis ${ }^{5}$ \\ ${ }^{1}$ Department Community and Family Medicine, Division of Community Medicine, College of Medicine, Jouf University, \\ Sakaka 72388, Saudi Arabia \\ ${ }^{2}$ Department of Public Health, Ministry of Health, Riyadh 11176, Saudi Arabia \\ ${ }^{3}$ Department Community and Family Medicine, Division of Family Medicine, College of Medicine, Jouf University, \\ Sakaka 72388, Saudi Arabia \\ ${ }^{4}$ Department of Academic Affairs and Training, Ministry of Health, Tabuk Region 47312, Saudi Arabia \\ ${ }^{5}$ Department of Public Health, Ministry of Health, Tabuk Region 47312, Saudi Arabia
}

Correspondence should be addressed to Ashokkumar Thirunavukkarasu; ashokkumar@ju.edu.sa

Received 18 November 2021; Accepted 23 December 2021; Published 13 January 2022

Academic Editor: Mona Hassan

Copyright (C) 2022 Ashokkumar Thirunavukkarasu et al. This is an open access article distributed under the Creative Commons Attribution License, which permits unrestricted use, distribution, and reproduction in any medium, provided the original work is properly cited.

\begin{abstract}
Oral health-related quality of life (OHRQoL) is an essential indicator of people's overall health and health-related quality of life. Poor oral health and OHRQoL among young adults lead to numerous negative consequences and an increased burden on the healthcare system. The present study is aimed at assessing the OHRQoL among the young adults of Saudi Arabia, identifying self-rated oral health, and determining the relationship between sociodemographic and lifestyle factors with the OHRQoL. The present analytical cross-sectional survey was conducted among 1152 health and non-health-related college university students from three randomly selected universities. The OHRQoL was evaluated using the validated Arabic version of the oral health impact profile-14 questionnaire (OHIP-14). Of the population studied, one-fourth of the participants (24.9\%) reported poor or fair oral health, and the highest OHIP-14 score was found in the domains of physical pain (4.14), followed by psychological discomfort (4.07). Logistic regression analysis revealed that the poor oral health category was significantly associated with male gender (ref: female: adjusted $\mathrm{OR}(\mathrm{AOR})=1.89,95 \% \mathrm{CI}=1.23-2.94$, $p=0.004$ ), daily smokers (ref: nonsmokers: $\mathrm{AOR}=3.47,95 \% \mathrm{CI}=1.97-4.82, p<0.001$ ), chocolate and candies intake more than once a day (ref: never; $\mathrm{AOR}=1.54,95 \% \mathrm{CI}=1.10-2.19, p=0.034$ ), and did not seek periodical dental care (ref: periodic dental care received: $\mathrm{AOR}=2.23,95 \% \mathrm{CI}=1.53-2.86, p=0.002)$. The present study revealed the factors associated with poor OHRQoL. The concerned authorities should consider the implementation of periodic dental checkups for university students, especially for the high-risk group. Furthermore, it is recommended to have regular health education programs that will help to change the student's lifestyle and poor oral health behaviors.
\end{abstract}

\section{Introduction}

Health is "a state of complete physical, mental, and social well-being, not merely the absence of disease and infirmity" as defined by the World Health Organization (WHO) [1].
Oral health $(\mathrm{OH})$ is an essential indicator of people's general health and is closely associated with overall health and health-related quality of life (HRQoL) [2, 3]. HRQoL is an appropriate index for assessing people's overall health and the effect of health conditions on the quality of life [4]. 
Understanding the health and quality of life leads us to understand the concept of oral health-related quality of life (OHRQoL) [5]. OHRQoL represents the subjective experience of symptoms related to oral conditions that impact the well-being of an individual. The OHRQoL uses patientcentered outcome measures to identify the impact of $\mathrm{OH}$ on aspects of everyday life regarding social, psychological, and functional well-being $[5,6]$. Poor $\mathrm{OH}$ and OHRQoL among people lead to numerous negative consequences, including low self-esteem, depression, decreased performance in daily activities, lack of social interaction, and an increased burden on the healthcare system $[3,7]$.

Over the past decades, a set of psychometric instruments have been developed to assess OHRQoL $[8,9]$. The OH impact profile (OHIP) questionnaire is commonly used to measure OHRQoL in children, adults, and dentate elderly people [10, 11]. The short version of the OHIP includes 14 items (OHIP-14), which are based on Locker's conceptual model to measure $\mathrm{OH}$ [10]. These elements represent the consequences of oral diseases and the negative impact they have on OHRQoL. The validity and reliability of OHIP-14 have been shown in many studies, and the instrument has been translated and validated into several languages including Arabic language [9, 12-15]. The factors that affect self-reported $\mathrm{OH}$ are not clear, but it has been suggested that oral diseases have a detrimental effect on subjective $\mathrm{OH}$, and that effect is likely to be greater at younger ages. Studies reported that young and middle-aged adults report worse $\mathrm{OH}$ than older adults, although oral problems tend to increase with age $[16,17]$.

In a study conducted by Wei et al. among Japanese students, they reported that young university students are in a dynamic transition period of growth and development that bridges adolescence to adulthood (people in the community) [18]. Many of them start to live away from their homes for the first time in their lives, which can adversely affect their health, lifestyle, and behavior. As a result of these physiological and social changes, their oral health behaviors and their clinical status can quickly deteriorate $[18,19]$. Furthermore, poor oral health behaviors, such as high sugar consumption and inadequate brushing habits, may lead to adverse effects on OHRQoL [19, 20].

In the Kingdom of Saudi Arabia (KSA), some authors have attempted to identify the OHRQoL in different settings. Most of the studies that assessed OHRQoL were among patients with a dental problem or elderly participants [14, 17]. Despite the evidence on the importance of OHRQoL assessment among apparently healthy young adults and university students, there is limited data available in the KSA. Considering the necessity of having regional data in this category population, this study was planned to assess the OHRQoL among the young adults of the KSA by using the OHIP14 questionnaire. The present study is also aimed at determining the relationship between OHRQoL and self-rated oral health among them and to find the association between sociodemographic and lifestyle factors with OHRQoL.

\section{Participants and Methods}

2.1. Study Description. This multicenter cross-sectional study was carried out among students (aged 18-25) from different colleges (health- and non-health-related colleges) from three universities of the KSA, namely, Jouf University, Northern Border University, and King Saud University.

2.2. Sample Size Estimation. The minimum required participants for this study was estimated based on Cochran's formula for sample size estimation, $n=z^{2} p q / e^{2}$. In this formula, $z=1.96$ in the $95 \%$ confidence interval, $e$ is in the $5 \%$ error margin, $p$ is the expected proportion, and $q$ is $1 p$. Since studies that assessed OHRQoL among the KSA population had depicted huge variations in prevalence in this subject, we have taken a $50 \%$ population proportion $(p)$ to obtain a maximum sample size. After applying all the values in Cochran's formula, the estimated minimum required sample for the current survey was 384. The present study included 384 students from each university, and the total estimated sample size was $1152(3 \times 384)$.

2.3. Sampling Method. The required number of sample participants was selected by a multistage probability proportional to size (PPS) sampling technique. In this technique, first, two health science colleges and two other colleges were randomly selected using the lot method from each of the three universities. Only a college with both sections (boys and girls) is included. In the following stages, the required number of participants from each college was selected according to gender and year of the students. Finally, the systematic random sampling method was used based on students' university identification numbers to select participants from each year of education.

2.4. Data Collection Method. We have begun the data collection process after ethical approvals obtained from concerned authorities and other necessary administrative permissions. The data collector contacted the selected student during the self-directed learning period with the help of their class leader. After briefly explaining about the survey and getting informed consent, the students filled the data collection form (Google form) in the data collector's electronic device (mobile, tab, or laptop). Only the principal investigator was authorized to access the Google form of the current survey. Students who were not willing to participate or were unavailable during data collection were considered nonrespondents and were replaced by the next student according to the university identification number.

2.5. Data Collection Tool. This research data were collected by using an open-source, structured, and validated selfadministered Arabic questionnaire [15] consisting of three parts. The first part inquired about sociodemographic and oral health-related behaviors such as intake of candies, sugary drinks, and brushing teeth. The second part inquired about the participants' perceptions of their oral health by asking through a question "What is your perception of your oral health?," and the responses were recorded from poor to excellent. Finally, we assessed OHRQoL through OHIP-14. The OHIP-14 has 14 questions related to the evaluation of OHRQoL. The responses were recorded in a 5-point Likert scale ranging from never to very often (score is 0 to 4 ). Then, we calculated the total scores of all domains, and a higher 
score indicated poor OHRQoL. The highest possible total score of all the OHIP-14 domains is $56(14 \times 4)$. Furthermore, OHRQoL was further categorized into good, for whom score was less than $60 \%$ of the total possible score $(<35)$, and poor for whom score was more than or equal to $60 \%$ of the total possible score $(\geq 35)$. The OHIP-14 assesses seven domains in a broad area ranging from functional and social to psychological discomfort caused by their oral health conditions $[9,11]$. The present study used an open-source Arabic version of the OHIP-14 tool, validated by Habashneh et al. among Jordanian adults (satisfactory Cronbach's alpha value $>70$ ) [15]. A pilot study was carried out among 30 health and non-health science college students in our region with the adapted Arabic questionnaire. The Cronbach alpha value of the pilot study was 0.89 , which exhibited good internal consistency. Hence, the research team proceeded to collect the main study data using this standard and validated Arabic questionnaire.

2.6. Data Analysis. The Microsoft Excel sheet downloaded from Google form was exported to Statistical Package for the Social Sciences (SPSS) version 21. Then, we recoded all the variables in SPSS as per the predefined data coding sheet for further analysis. Descriptive data from this study were presented as frequency and proportion $(n ; \%)$ for qualitative variables, while quantitative variables were shown as the mean \pm SD for age in sociodemographic characteristics. Initially, the research team performed the Shapiro-Wilk test for normality assumption. The Kruskal-Wallis test was applied to find the association between perceived oral health status and OHIP-14 scores. The binomial logistic regression (enter method) analysis was executed to determine the relationship between oral health category status and sociodemographic factors, lifestyle factors, and oral health behaviors. In this enter method, the adjusted covariables were age in years, gender, college type, year of education, smoking status, carbonated drink intake, chocolates, candies consumption, brushing count, and periodic dentist care. This study's statistical tests were two-tailed, and a $p$ value less than 0.05 was set as statistically significant value.

\section{Results}

Of the 1152 studied participants, the mean (SD) age was 20.98 (1.9), 51.6\% were females, the majority (57.5\%) were from non-health-related colleges, and more than threefourth $(80.6 \%)$ were nonsmokers. Almost a third of the participants were taking carbonated drinks daily (34.8\%) and consuming chocolates and candies (34.4\%) daily. Regarding oral health-related behaviors, $59.4 \%$ of the participants were brushing teeth once a day and a majority $(60.1 \%)$ of them never visited dental healthcare providers periodically (Table 1).

The participants' responses in each item of the OHIP-14 questionnaire are presented in Table 2. The majority (76.4\%) of the study participants never had trouble pronouncing words, two-third (67.1) of the participants never had difficulty doing their usual jobs, and $6.5 \%$ of students were self-conscious due to their oral health.
TABlE 1: Distribution of study participants according to sociodemographic characteristics, lifestyle factors, and oral health behaviors.

\begin{tabular}{|c|c|c|}
\hline Characteristics & Number & $\%$ \\
\hline Age $($ mean $\pm S D)$ & \multicolumn{2}{|c|}{$20.98 \pm 1.9$} \\
\hline $\begin{array}{l}\text { Gender } \\
\text { Male } \\
\text { Female }\end{array}$ & $\begin{array}{l}594 \\
558\end{array}$ & $\begin{array}{l}51.6 \\
48.4\end{array}$ \\
\hline $\begin{array}{l}\text { College type } \\
\text { Healthcare-related college } \\
\text { Other colleges }\end{array}$ & $\begin{array}{l}490 \\
662\end{array}$ & $\begin{array}{l}42.5 \\
57.5\end{array}$ \\
\hline $\begin{array}{l}\text { Year of education } \\
\text { First } \\
\text { Second } \\
\text { Third } \\
\text { Fourth } \\
\text { Fifth }\end{array}$ & $\begin{array}{l}303 \\
240 \\
233 \\
154 \\
222\end{array}$ & $\begin{array}{l}26.3 \\
20.8 \\
20.2 \\
13.4 \\
19.3\end{array}$ \\
\hline $\begin{array}{l}\text { Smoking/shisha habits } \\
\text { No } \\
\text { Yes: daily } \\
\text { Yes: rarely }\end{array}$ & $\begin{array}{c}928 \\
156 \\
68\end{array}$ & $\begin{array}{c}80.6 \\
13.5 \\
5.9\end{array}$ \\
\hline $\begin{array}{l}\text { Carbonated drink consumption } \\
\text { Never } \\
\text { Once a day } \\
\text { Seldom/rarely }\end{array}$ & $\begin{array}{l}152 \\
401 \\
599\end{array}$ & $\begin{array}{l}13.2 \\
34.8 \\
52.0\end{array}$ \\
\hline $\begin{array}{l}\text { Consumption of chocolates and candies } \\
\text { Never } \\
\text { Seldom/rarely } \\
\text { Once daily } \\
\text { More than once a day }\end{array}$ & $\begin{array}{c}45 \\
525 \\
397 \\
185\end{array}$ & $\begin{array}{l}3.9 \\
45.6 \\
34.4 \\
16.1\end{array}$ \\
\hline $\begin{array}{l}\text { Brushing teeth per day } \\
\text { Once } \\
\text { Twice or more }\end{array}$ & $\begin{array}{l}684 \\
468\end{array}$ & $\begin{array}{l}59.4 \\
40.6\end{array}$ \\
\hline $\begin{array}{l}\text { Visit to the dental provider periodically } \\
\text { (every } 6 \text { months) } \\
\text { Yes } \\
\text { No }\end{array}$ & $\begin{array}{l}460 \\
692\end{array}$ & $\begin{array}{l}39.9 \\
60.1\end{array}$ \\
\hline
\end{tabular}

Figure 1 shows the distribution of mean scores in seven domains of the OHIP-14. Of the participants studied, the highest score was found for physical pain (4.14), followed by psychological discomfort (4.07) and psychological disability (3.73). The mean total score of all seven domains was $24.69 \pm 5.2$.

Table 3 shows that almost one-third (34.4\%) of the participants reported good oral health. Furthermore, the combined OHIP-14 scores the self-rated oral health were assessed by the Kruskal-Wallis (nonparametric) test. Of the sample studied, there was a significant association between self-rated oral health $(p<0.001)$ and pain or discomfort in teeth or gum or mouth $(p=0.012)$ with the OHIP-14 scores.

The participants were further classified into good $(<35$ of total score) and poor ( $\geq 35$ of total score) OHRQoL categories. Of the 1152 university students who participated, 197 $(17.1 \%)$ were in the poor oral health category and 955 $(82.9 \%)$ were in the good OHRQoL categories (Figure 2). These categories were used for logistic regression analysis. 
TABLE 2: Frequency of responses in each domain of OHIP-14. The data shown below are frequency and proportion; $n$ (\%).

\begin{tabular}{|c|c|c|c|c|c|c|}
\hline Domains & Items & Never & Hardly ever & Occasionally & Fairly often & Very often \\
\hline \multirow{2}{*}{ Functional limitations } & Trouble pronouncing words & $880(76.4)$ & $106(9.2)$ & $108(9.4)$ & $39(3.4)$ & $19(1.6)$ \\
\hline & Taste worsened & $808(70.1)$ & $166(14.4)$ & $139(12.1)$ & $31(2.7)$ & $8(0.7)$ \\
\hline \multirow{2}{*}{ Physical pain } & Aching mouth & $464(40.3)$ & $354(30.7)$ & $214(18.6)$ & $89(7.7)$ & $31(2.7)$ \\
\hline & Discomfort in eating food & $439(38.1)$ & $291(25.3)$ & $291(25.2)$ & $100(8.7)$ & $31(2.7)$ \\
\hline \multirow{2}{*}{ Psychological discomfort } & Being self-conscious & $530(46.0)$ & $206(17.9)$ & $230(20.0)$ & $111(9.6)$ & $75(6.5)$ \\
\hline & Feeling nervous & $600(52.1)$ & $206(17.9)$ & $213(18.5)$ & $82(7.1)$ & $51(4.4)$ \\
\hline \multirow{2}{*}{ Physical disability } & Unsatisfactory diet & $797(69.2)$ & $158(13.7)$ & $118(10.2)$ & $50(4.3)$ & $29(2.5)$ \\
\hline & Interrupting meals & $651(56.5)$ & $268(23.3)$ & $160(13.9)$ & $44(3.8)$ & $29(2.5)$ \\
\hline \multirow{2}{*}{ Psychological disability } & Embarrassed & $609(52.9)$ & $275(23.9)$ & $181(15.7)$ & $63(5.5)$ & $24(2.1)$ \\
\hline & Difficulty relaxing & $607(52.7)$ & $205(17.8)$ & $213(18.5)$ & $72(6.3)$ & $55(4.8)$ \\
\hline \multirow{2}{*}{ Social disability } & Irritable with other people & $645(56.0)$ & $202(17.5)$ & $195(16.9)$ & $69(6.0)$ & $41(3.6)$ \\
\hline & Difficulty doing usual jobs & $773(67.1)$ & $201(17.4)$ & $118(10.2)$ & $45(3.9)$ & $15(1.3)$ \\
\hline \multirow{2}{*}{ Handicap } & Life less satisfying & $789(68.5)$ & $164(14.2)$ & $115(10.0)$ & $54(4.7)$ & $30(2.6)$ \\
\hline & Unable to function & $790(68.6)$ & $181(15.7)$ & $119(10.3)$ & $38(3.3)$ & $24(2.1)$ \\
\hline
\end{tabular}

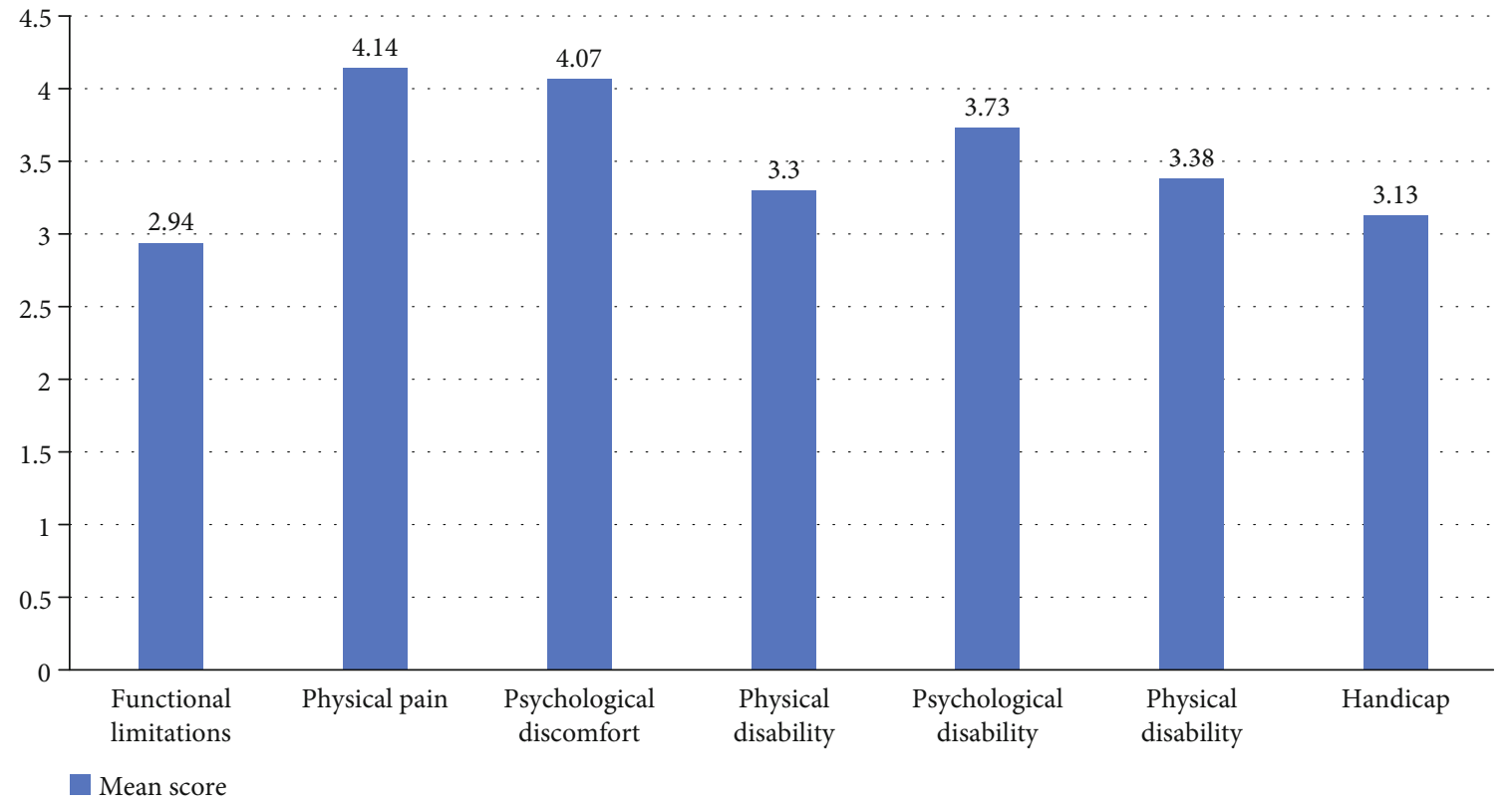

Figure 1: Mean score distribution in different OHIP-14 domains.

The results of binomial logistic regression analysis that was done to find the relationship between oral health category status with the sociodemographic characters, lifestyle factors, and oral health behaviors are presented in Table 4 . The poor oral health category was significantly associated with male gender (ref: female: $\mathrm{AOR}=1.89,95$ $\% \mathrm{CI}=1.23-2.94, \quad p=0.004$ ), daily smokers (ref: nonsmokers: $\mathrm{AOR}=3.47,95 \% \mathrm{CI}=1.97-4.82, p<0.001)$, chocolate and candies intake more than once a day (ref: never; $\mathrm{AOR}=1.54,95 \% \mathrm{CI}=1.10-2.19, p=0.034$ ), and not seeing the dental care provider periodically (ref: periodic dental care: $\mathrm{AOR}=2.23,95 \% \mathrm{CI}=1.53-2.86, p=0.002$ ).

\section{Discussion}

"World oral health day" is observed annually on the 20th of March by the World Dental Federation to reduce the burden of oral diseases. Their campaign theme 2021-2023 focused on inspiring the people on the importance of oral health for its positive effect on general health, well-being, and overall healthy life [21]. This reiterates the importance of assessing OHRQoL among young adults for preventive measures to improve their overall health, as they will be the future of a country. 
TABLE 3: Association between combined OHIP-14 scores with self-rated oral health and pain or discomfort in the mouth*

\begin{tabular}{lcc}
\hline Variable & $n(\%)$ & Mean $( \pm$ SD $)$ \\
\hline Self-rated oral health & $179(15.5)$ & $14.6(3.7)$ \\
Poor & $108(9.4)$ & $13.3(2.7)$ \\
Fair & $396(34.4)$ & $13.9(3.4)$ \\
Good & $346(30.0)$ & $11.3(2.7)$ \\
Very good & $123(10.7)$ & $10.4(3.2)$ \\
Excellent & & \\
Pain or discomfort in teeth or gum or mouth & $303(26.3)$ & $11.1(2.6)$ \\
Never & $344(29.9)$ & $11.8(3.1)$ \\
Rarely & $372(32.3)$ & $12.8(3.3)$ \\
Sometimes & $133(11.5)$ & $13.4(3.8)$ \\
Often & & 0.012 \\
\hline
\end{tabular}

${ }^{*}$ Kruskal-Wallis test.

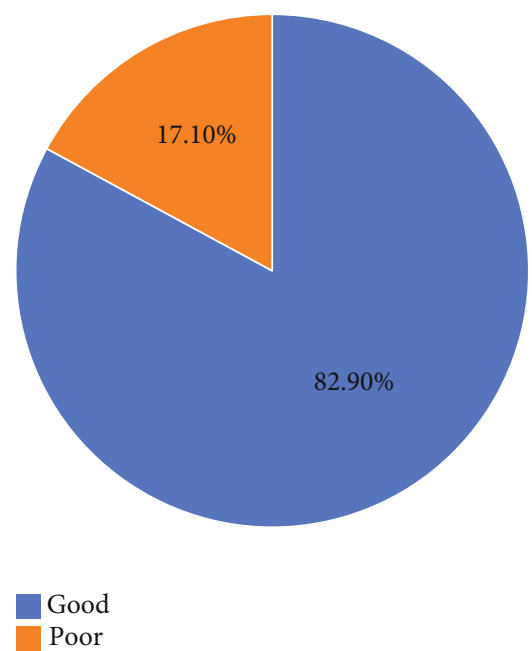

Figure 2: Overall OHRQoL category $(n=1152)$.

Previous researchers worldwide stated that self-rated $\mathrm{OH}$ is one of the critical links and predictors of the general health status of the public $[22,23]$. The present study findings revealed that one-fourth $(24.9 \%)$ of the participants perceived their $\mathrm{OH}$ status as either poor or fair. A survey conducted by Drachev et al. among Russian university students also revealed similar findings [24]. In contrast, a study done by Moreas et al. has shown a higher proportion of poor self-rated health. This difference in results could be described due to the study settings, inclusion criteria, and methods used. The present study included young adults of both sexes studying at the university, while the latter included only women from a Brazilian community [25]. The present study revealed a positive association between the OHIP-14 scores and self-oral rated health $(p<0.001)$. This study finding is supported by researches of Verhulst et al. and Drachev et al. [23, 24]. Those studies also reported a positive association between perceived poor oral health status and the OHIP-14 scores. These findings again confirm that self-rated oral health is one of the strongest predictors of the OHRQoL and general health.
The results of the current study indicated that the highest OHIP score was found in physical pain, followed by the domains of psychological discomfort and psychological disability domains. Similarly, a study conducted in Jazan city of Saudi Arabia also found that physical pain and psychological discomfort domains had higher OHIP scores than the rest of the domains [14]. Interestingly, a study done by Papaioannou et al. among the Greek population revealed that high scores were determined in functional limitation, physical pain, and handicap domains [26]. This dissimilarity could be justified by the variations in the incorporation of the survey participants. The current study included university students from health and other colleges, while Papaioannou et al. surveyed the adults from rural and urban communities.

On assessing the association between sociodemographic characteristics with the poor OHRQoL, the present study found that male participants had a significantly higher rate of poor OHRQoL $(\mathrm{AOR}=1.89,95 \% \mathrm{CI}=1.23-2.94, p=0.004)$ than females. However, previously published studies around the world reported different findings. For example, a study done in China by Lu et al. did not find any differences between genders and OHRQoL [27], and a study by Drachev et al. in Russia reported a higher rate of low OHRQoL [24].

This study revealed that poor OHRQoL was significantly higher among the daily smokers $(\mathrm{AOR}=3.47,95 \% \mathrm{CI}=1.97$ $-4.82, p<0.001)$. Similar to the current study findings, most previous studies also reported a significant association between smokers and poor OHRQoL [28, 29]. Numerous mechanisms explain this striking association between smoking and oral health, including decreased blood flow, increased local edema, and inflammation [30, 31].

Although there are many debates about the periodic screening interval for preventive dental care, the American Dental Association suggested dental screening and evaluation every six months. The current study reported that $60.1 \%$ of the participants did not seek dental care providers periodically. The poor OHRQoL was significantly higher among the students who did not visit dental healthcare providers regularly $(\mathrm{AOR}=2.23,95 \% \mathrm{CI}=1.53-2.86, p=$ $0.002)$. Some researchers have previously evaluated the effectiveness of periodic dental screening $[32,33]$. In the KSA, 
TABLE 4: Relationship of the OHRQoL category with sociodemographic characters, lifestyle factors, and oral health behaviors.

\begin{tabular}{|c|c|c|c|c|c|}
\hline \multirow[t]{2}{*}{ Characteristics } & \multirow[t]{2}{*}{ Total sample (1152) } & \multicolumn{2}{|c|}{ Poor OHRQoL } & \multicolumn{2}{|c|}{ Binomial logistic regression } \\
\hline & & No & Yes & Adjusted OR (95\% CI) & $p$ value \\
\hline Age (mean $\pm \mathrm{SD})$ & & $8 \pm 1.9$ & & $0.958(0.835-1.09)$ & 0.533 \\
\hline $\begin{array}{l}\text { Gender } \\
\text { Female } \\
\text { Male }\end{array}$ & $\begin{array}{l}558 \\
594\end{array}$ & $\begin{array}{l}470(84.2) \\
485(81.6)\end{array}$ & $\begin{array}{c}88(15.8) \\
109(18.4)\end{array}$ & $\begin{array}{c}\text { Ref } \\
1.89(1.23-2.94)\end{array}$ & 0.004 \\
\hline $\begin{array}{l}\text { College type } \\
\text { Healthcare-related college } \\
\text { Other colleges }\end{array}$ & $\begin{array}{l}490 \\
662\end{array}$ & $\begin{array}{l}396(80.8) \\
559(84.4)\end{array}$ & $\begin{array}{c}94(19.2) \\
103(15.6)\end{array}$ & $\begin{array}{c}\text { Ref } \\
1.35(0.94-1.93)\end{array}$ & 0.108 \\
\hline $\begin{array}{l}\text { Year of education } \\
\text { First } \\
\text { Second } \\
\text { Third } \\
\text { Fourth } \\
\text { Fifth/intern }\end{array}$ & $\begin{array}{l}303 \\
240 \\
233 \\
154 \\
222\end{array}$ & $\begin{array}{l}259(85.5) \\
187(77.9) \\
187(80.3) \\
129(83.8) \\
193(86.9)\end{array}$ & $\begin{array}{l}44(14.5) \\
53(22.1) \\
46(19.7) \\
25(12.7) \\
29(13.1)\end{array}$ & $\begin{array}{c}\text { Ref } \\
0.81(0.65-1.35) \\
1.19(0.67-2.11) \\
0.76(0.58-1.36) \\
0.85(0.53-1.41)\end{array}$ & $\begin{array}{l}0.101 \\
0.553 \\
0.478 \\
0.688\end{array}$ \\
\hline $\begin{array}{l}\text { Smoking/shisha habits } \\
\text { No } \\
\text { Yes: daily } \\
\text { Yes: rarely }\end{array}$ & $\begin{array}{c}928 \\
156 \\
68\end{array}$ & $\begin{array}{c}785(84.6) \\
116(74.4) \\
54(79.4)\end{array}$ & $\begin{array}{l}143(15.4) \\
40(25.6) \\
14(20.6)\end{array}$ & $\begin{array}{c}\text { Ref } \\
3.47(1.97-4.82) \\
2.25(1.52-2.17)\end{array}$ & $\begin{array}{c}<0.001 \\
0.002\end{array}$ \\
\hline $\begin{array}{l}\text { Carbonated drink consumption } \\
\text { Never } \\
\text { Seldom/rarely } \\
\text { Once daily }\end{array}$ & $\begin{array}{l}152 \\
599 \\
401\end{array}$ & $\begin{array}{l}125(82.2) \\
488(81.5) \\
342(85.3)\end{array}$ & $\begin{array}{c}27(17.8) \\
111(18.5) \\
59(14.7)\end{array}$ & $\begin{array}{c}\text { Ref } \\
0.621(0.34-1.14) \\
0.971(0.57-1.66)\end{array}$ & $\begin{array}{l}0.128 \\
0.916\end{array}$ \\
\hline $\begin{array}{l}\text { Consumption of chocolates and candies } \\
\text { Never } \\
\text { Seldom/rarely } \\
\text { Once daily } \\
\text { More than once in a day }\end{array}$ & $\begin{array}{c}45 \\
525 \\
397 \\
185\end{array}$ & $\begin{array}{l}39(86.7) \\
426(81.1) \\
325(81.9) \\
139(75.1)\end{array}$ & $\begin{array}{l}6(13.3) \\
99(18.9) \\
72(18.1) \\
46(23.4)\end{array}$ & $\begin{array}{c}\text { Ref } \\
0.98(0.75-1.74) \\
1.23(0.84-1.98) \\
1.54(1.10-2.19)\end{array}$ & $\begin{array}{l}0.969 \\
0.317 \\
0.034\end{array}$ \\
\hline $\begin{array}{l}\text { Brushing teeth per day } \\
\text { Twice or more } \\
\text { Once/never }\end{array}$ & $\begin{array}{l}468 \\
684\end{array}$ & $\begin{array}{l}403(86.1) \\
552(80.7)\end{array}$ & $\begin{array}{c}65(13.9) \\
132(19.3)\end{array}$ & $\begin{array}{c}\text { Ref } \\
0.78(0.56-1.34)\end{array}$ & 0.601 \\
\hline $\begin{array}{l}\text { Visit to the dental provider periodically } \\
\text { (every } 6 \text { months) } \\
\text { Yes } \\
\text { No }\end{array}$ & $\begin{array}{l}460 \\
690\end{array}$ & $\begin{array}{l}408(88.7) \\
545(78.9)\end{array}$ & $\begin{array}{c}52(11.3) \\
145(21.1)\end{array}$ & $\begin{array}{c}\text { Ref } \\
2.23(1.53-2.86)\end{array}$ & 0.002 \\
\hline
\end{tabular}

Variable(s) entered on step 1: age in years, gender, college type, year of education, smoking status, carbonated drink intake, chocolates and candies consumption, brushing per day, and periodic dentist care.

the Ministry of Health has established a dental screening program among schoolchildren. However, no structured dental screening program is implemented in university facilities for students.

Despite the best efforts made by the present survey team on this study with a standard methodology, certain constraints are to be noted while reading the findings of the current survey. Firstly, this survey is a questionnairebased and self-reported. Hence, recall bias, exaggerated responses, and selection bias are to be considered while interpreting the findings of this survey. Secondly, this cross-sectional study attempted to find the association, and not the causation, between the variables.

\section{Conclusions}

The study findings suggest that self-rated poor oral health is significantly associated with OHIP-14 scores. The present study revealed the factors associated with poor OHRQoL. Physical pain and psychological discomfort were the most common domain with high OHIP scores. The concerned authorities should consider the implementation of periodic dental checkups for university students, especially for the high-risk group. Furthermore, regular health education programs that help change the student's lifestyle and oral health behaviors must be arranged. Finally, an exploratory multicenter study is warranted that compares OHRQoL with the actual oral status of the students.

\section{Data Availability}

The data used to support the findings of this study will be provided from the corresponding author on request.

\section{Conflicts of Interest}

The authors declare that there is no conflict of interest regarding the publication of this paper. 


\section{Acknowledgments}

We would like to thank Sayyaf Ayed Abdullah Alanazi, Hussam Ali Hasan Alrased, Mohamed Ali Hasan Alrased, Abdulaziz Ayead Alanazi, Hatim Ahmed Almufadhi, and the Jouf University students for their contribution to data collection for this research. We also extend our sincere thanks to all the students who participated in this research project. This work was funded by the Deanship of Scientific Research at Jouf University under grant No. DSR-2021-01-03143.

\section{References}

[1] WHO, Constitution of the World Health Organizationhttps:// www.who.int/about/governance/constitution.

[2] W. Sabbah, M. O. Folayan, and M. El Tantawi, "The link between oral and general health," International Journal of Dentistry, vol. 2019, Article ID 7862923, 2 pages, 2019.

[3] J. M. Kieffer and J. Hoogstraten, "Linking oral health, general health, and quality of life," European Journal of Oral Sciences, vol. 116, no. 5, pp. 445-450, 2008.

[4] M. Karimi and J. Brazier, "Health, health-related quality of life, and quality of life: what is the difference?," PharmacoEconomics, vol. 34, no. 7, pp. 645-649, 2016.

[5] D. Bennadi and C. Reddy, "Oral health related quality of life," Journal of International Society of Preventive \& Community Dentistry, vol. 3, no. 1, pp. 1-6, 2013.

[6] A. Mehta and G. Kaur, "Oral health-related quality of life-the concept, its assessment and relevance in dental research and education," Indian Journal of Dentistry, vol. 2, no. 2, pp. 2629, 2011.

[7] S. F. Kane, "The effects of oral health on systemic health," General Dentistry, vol. 65, no. 6, pp. 30-34, 2017.

[8] D. R. Reissmann, "Methodological considerations when measuring oral health-related quality of life," Journal of Oral Rehabilitation, vol. 48, no. 3, pp. 233-245, 2021.

[9] D. Adamo, G. Pecoraro, G. Fortuna et al., "Assessment of oral health-related quality of life, measured by OHIP-14 and GOHAI, and psychological profiling in burning mouth syndrome: a case-control clinical study," Journal of Oral Rehabilitation, vol. 47, no. 1, pp. 42-52, 2020.

[10] E. Mijiritsky, Y. Lerman, O. Mijiritsky, A. Shely, J. Meyerson, and M. Shacham, "Development and validation of a questionnaire evaluating the impact of prosthetic dental treatments on patients' oral health quality of life: a prospective pilot study," International Journal of Environmental Research and Public Health, vol. 17, no. 14, p. 5037, 2020.

[11] M. F. Silveira, L. D. Pinho, and M. F. Brito, "Validity and reliability of the oral health impact profile instrument (OHIP-14) in adolescents,” Paidéia (Ribeirão Preto), vol. 29, 2019.

[12] S. Verma and H. Sharma, "Translation and validation of Hindi version of oral health impact profile-14, a measure of oral health-related quality of life of geriatrics," Indian Journal of Dental Research, vol. 30, no. 2, pp. 180-184, 2019.

[13] L. Hongxing, T. List, I. M. Nilsson, A. Johansson, and A. N. Astrøm, "Validity and reliability of OIDP and OHIP-14: a survey of Chinese high school students," BMC Oral Health, vol. 14, no. 1, p. 158, 2014.

[14] Z. Hakami, H. S. Chung, S. Moafa et al., "Impact of fashion braces on oral health related quality of life: a web-based cross-sectional study," BMC Oral Health, vol. 20, no. 1, pp. 1-9, 2020.

[15] R. A. Habashneh, Y. S. Khader, and S. Salameh, "Use of the Arabic version of Oral Health Impact Profile-14 to evaluate the impact of periodontal disease on oral health-related quality of life among Jordanian adults," Journal of Oral Science, vol. 54, no. 1, pp. 113-120, 2012.

[16] E. Hadler-Olsen and B. Jönsson, "Oral health and use of dental services in different stages of adulthood in Norway: a cross sectional study," BMC Oral Health, vol. 21, no. 1, p. 257, 2021.

[17] M. Alshammari, M. A. Baseer, N. A. Ingle, M. K. Assery, and M. A. al Khadhari, "Oral health-related quality of life among elderly people with edentulous jaws in Hafar Al-Batin Region, Saudi Arabia," Journal of International Society of Preventive \& Community Dentistry, vol. 8, no. 6, pp. 495-502, 2018.

[18] C.-N. Wei, K. Harada, K. Ueda, K. Fukumoto, K. Minamoto, and A. Ueda, "Assessment of health-promoting lifestyle profile in Japanese university students," Environmental Health and Preventive Medicine, vol. 17, no. 3, pp. 222-227, 2012.

[19] V. Pohjola, M. Nurkkala, and J. I. Virtanen, "Psychological distress, oral health behaviour and related factors among adolescents: Finnish School Health Promotion Study," BMC Oral Health, vol. 21, no. 1, p. 6, 2021.

[20] M. Lutovac, O. V. Popova, G. Macanovic et al., "Testing the effect of aggressive beverage on the damage of enamel structure," Open Access Macedonian Journal of Medical Sciences, vol. 5, no. 7, pp. 987-993, 2017.

[21] FDI, World Oral Health Day: Campaign theme (20212023)https://www.worldoralhealthday.org/campaign-theme2021-2023.

[22] M. N. Alhajj, E. Halboub, A. G. Amran et al., "Link between perceived oral and general health status among Yemeni adult dental patients," BMC Oral Health, vol. 19, no. 1, pp. 1-9, 2019.

[23] M. J. Verhulst, W. Teeuw, V. Gerdes, and B. Loos, "Selfreported oral health and quality of life in patients with type 2 diabetes mellitus in primary care: a multi-center crosssectional study," Diabetes, metabolic syndrome and obesity: targets and therapy, vol. 12, pp. 883-899, 2019.

[24] S. N. Drachev, T. Brenn, and T. A. Trovik, "Oral health-related quality of life in young adults: a survey of Russian undergraduate students," International Journal of Environmental Research and Public Health, vol. 15, no. 4, p. 719, 2018.

[25] L. R. Moraes, L. C. Duarte de Aquino, D. T. . Cruz, and I. C. G. Leite, "Self-perceived impact of oral health on the quality of life of women deprived of their liberty," International Journal of Dentistry, vol. 2021, 10 pages, 2021.

[26] W. Papaioannou, C. J. Oulis, D. Latsou, and J. Yfantopoulos, "Oral health-related quality of life of Greek adults: a crosssectional study," International journal of dentistry, vol. 2011, 7 pages, 2011.

[27] H.-X. Lu, M. C. M. Wong, E. C. M. Lo, and C. McGrath, "Oral health related quality of life among young adults," Applied Research in Quality of Life, vol. 10, no. 1, pp. 37-47, 2015.

[28] R. A. Sagtani, S. Thapa, and A. Sagtani, "Smoking, general and oral health related quality of life-a comparative study from Nepal," Health and Quality of Life Outcomes, vol. 18, no. 1, pp. 1-7, 2020.

[29] N. N. Bakri, G. Tsakos, and M. Masood, "Smoking status and oral health-related quality of life among adults in the United Kingdom," British Dental Journal, vol. 225, no. 2, pp. 153$158,2018$. 
[30] S. Tomar, S. S. Hecht, I. Jaspers, R. L. Gregory, and I. Stepanov, "Oral health effects of combusted and smokeless tobacco products," Advances in Dental Research, vol. 30, no. 1, pp. 4-10, 2019.

[31] CDC, Smoking, gum disease, and tooth loss, 2021, https://www .cdc.gov/tobacco/campaign/tips/diseases/periodontal-gumdisease.html.

[32] S. Scherr, S. Idzik, and D. Williams, "Integrating oral health screening into primary care to promote dental referrals in Maryland," Journal of Doctoral Nursing Practice, vol. 13, no. 1 , pp. 42-63, 2020.

[33] H. Alayadi, W. Sabbah, and E. Bernabé, "Effectiveness of school dental screening on dental visits and untreated caries among primary schoolchildren: study protocol for a cluster randomised controlled trial," Trials, vol. 19, no. 1, pp. 1-7, 2018. 